Didáctica Geográfica n 21, 2020,pp. 247-264

DOI: https://doi.org/10.21138/DG.548

ISSN electrónico: 2174-6451

\title{
LA FUENTE DEL BERRO: UNA QUINTA Y PARQUE SINGU- LAR EN EL MADRID CONTEMPORÁNEO (PAISAJE, ME- MORIA Y CONOCIMIENTO DEL MEDIO)
}

\author{
The Berro Fountain: a COUntry house AND Singular Park in \\ CONTEMPORARY MADRID (LANDSCAPE, MEMORY AND KNOWLEDGE OF \\ THE ENVIRONMENT)
}

LA fontaine Berro: Une maison de CHAMPagne et PARC UNiQUE DU MAdRID CONTEMPORAin (PAYSAge, MÉMOIRE ET CONNAISSANCE DE L'ENVIRONNEMENT)

Uxío-Breogán Diéguez Cequiel

Universidade da Coruña.

uxio.breogan.dieguez.cequiel@udc.gal

Recibido: 31/05/2020

Aceptado 02/10/2020

\section{RESUMEN:}

El espacio urbano ha ido construyéndose a costa del espacio rural, realidad que el público más joven desconoce, reduciéndose su relación con el mismo al ocio puntual (y con ello la función esencial de lo rural a lo largo de la historia del ser humano).

Incluso por parte de aquellos jóvenes que pudiesen tener abuelos que antaño hubiesen trabajado en el campo, lo rural es manifiestamente remoto y vinculado con duras faenas y desasosiegos. El tiempo en el que lo rural tenía una presencia muy notable no existe en la cosmovisión de los más jóvenes, incluso del profesorado en formación, aunque detrás 
de la realidad y epidermis urbana aflora la memoria del medio rural.

El presente texto intenta, por un lado, poner el foco sobre la evolución de la Quinta de La Fuente del Berro y su entorno más próximo, poniendo en valor las huellas y memoria del medio rural de los barrios madrileños de Las Ventas y de La Fuente del Berro, señalando por otra parte el importante potencial didáctico de esta parte del ensanche Este de la capital española.

\section{Palabras Clave:}

Fuente del Berro; didáctica de la geografía; memoria; enseñanza primaria; enseñanza secundaria.

\section{Abstract:}

Urban space has been built at the expense of rural space, a reality that the youngest public does not know, reducing its relationship with it to punctual leisure (and with it the essential function of the rural throughout the history of the human being).

Even on the part of those young people who may have grandparents who had once worked in the fields, the rural is manifestly remote and linked to hard work and restlessness. The time in which the rural population had a very notable presence does not exist in the worldview of the youngest, including the teachers in training, although behind the reality and urban epidermis the memory of the rural environment emerges.

This text tries, on the one hand, to focus on the evolution of the Quinta de La Fuente del Berro and its closest environment, highlighting the footprints and memory of the rural environment of the Madrid neighborhoods of Las Ventas and La Fuente del Berro, pointing out on the other hand the didactic potential of this part of the eastern expansion of the Spanish capital.

\section{KEYWORDS:}

Fuente del Berro; didactics of geography; memory; primary education; secondary education.

\section{RÉSUMÉ:}

L'espace urbain a été construit aux dépens de l'espace rural, réalité que le jeune public ignore, réduisant sa relation avec lui à des loisirs ponctuels (et avec lui la fonction essentielle du rural à travers l'histoire de l'être humain).

Même pour les jeunes qui pourraient avoir des grands-parents qui travaillaient autrefois dans les champs, les zones rurales sont manifestement isolées et liées à 
des tâches difficiles et à des troubles. L'époque où le rural avait une présence très notable n'existe pas dans la vision du monde des plus jeunes, même des enseignants en formation, bien que derrière la réalité et l'épiderme urbain se dégage la mémoire du milieu rural.

Ce texte tente, d'une part, de se concentrer sur l'évolution de la Quinta de La Fuente del Berro, et de ses environs les plus proches, en mettant en évidence les traces et la mémoire de l'environnement rural des quartiers madrilènes de Las Ventas et La Fuente del Berro en soulignant l'important potentiel d'enseignement de cette partie de l'expansion orientale de la capitale espagnole.

\section{MotS-CLÉS:}

Fuente del Berro; didactique de la géographie; mémoire; enseignement primaire; enseignement secondaire.

A la memoria de mi abuela $M^{a}$ Ángeles Paccini García (Madrid, 1924-Santiago de Compostela, 2009)

\section{INTRODUCCIÓN}

Una y otra vez parece que debemos justificar el cometido del estudio del espacio. Más allá de entender el espacio como realidad física, e incluso inmutable, debemos conceptualizarlo como escenario de realidades múltiples y, asimismo, como realidad dinámica. De tal modo que si ponemos el foco en el espacio urbano debemos explicarlo, a mi modo de ver, a partir del punto de cesura histórico que implicó el proceso de industrialización, realidad experimentada tardíamente para el caso español. Las actuales ciudades eran villas o pueblos, pequeñas/os, medianas/os o grandes, según el caso, que pasaron a desarrollarse industrialmente, sobre todo desde la segunda mitad del siglo XIX, en un primer momento, y desde finales de la década de 1950, en un segundo y definitivo momento histórico, para configurar el entorno urbano tal y como lo conocemos hoy. Una industrialización que significó una concentración de masa trabajadora con necesidades específicas de diversa índole (pensemos en viviendas, sanidad, educación, ocio, etcétera), que tuvo como efecto la ampliación de los lindes de aquellos espacios urbanos que actuaban de epicentro de atracción de ese proceso.

Para el caso del Estado español, Madrid y Barcelona han sido ciudades que han mutado especialmente en el marco de dicho proceso hasta nuestros días. 


\section{LA NECESIDAD DE EXPLICAR EL ESPACIO (Y SU EVOLUCIÓN EN EL TIEMPO)}

Pasadas dos décadas del siglo XXI debemos esforzarnos por explicar el medio físico desde este marco histórico, comprendiendo que las inmensas barriadas de estas y otras ciudades europeas no existían hace poco más de medio siglo (es decir, recientemente en larga perspectiva histórica). Con todo, parece que hace mucho más tiempo que existen esas fracciones de la ciudad y que la antesala de las mismas, con profundas raíces en el pasado, no ha dejado rastro alguno. Los barrios urbanos han significado la parcelación del espacio a lo largo de los años en calles, plazas y avenidas con nombres que honran/ recuerdan figuras y hechos ajenos al espacio al que dan nombre (aristócratas, políticos, deportistas...) y, a su vez, los habitantes que antaño vivían en ese espacio, y que durante siglos desarrollaron profesiones diversas (lo que conocemos como oficios tradicionales), no tienen presencia alguna.

Al hablar de la didáctica de la geografía en el ámbito escolar debemos reflexionar sobre por qué enseñar geografía, así como en lo relativo a qué aporta intelectualmente al alumnado el conocimiento geográfico, siendo necesario, tal y como indicaba Xosé Manuel Souto (1999, p. 92), "considerar qué puede aportar la geografía al papel de ciudadano que desarrollará el alumno en el futuro". En este sentido, propongo en el presente texto reflexionar sobre el conocimiento del espacio urbano en su interrelación geográfico-histórica, intentando vislumbrar como un parque actual puede contribuir para comprender y entender la evolución del espacio a lo largo del tiempo, y como este esfuerzo puede contribuir a valorar, más allá del mero ocio, un parque dentro de una gran urbe, como es el caso de La Fuente del Berro en el marco de Madrid.

\section{LA FUENTE DEL BERRO. EVOLUCIÓN HISTÓRICA DE UN ESPACIO NATURAL SINGULAR.}

El Madrid de finales del siglo XIX intentaba ampliar su espacio urbano intentando absorber más población de todo el Estado, en cuanto que capital del mismo, y para dar lugar a un nuevo gran cementerio. Así, pues, en 1880 Madrid compraría al ayuntamiento de Vicálvaro un inmenso terreno de 120 hectáreas (operación aprobada el 31 de octubre de 1879). Se sentarían las bases de la Necrópolis del Este de Madrid y del Cementerio Civil de Madrid, que se inauguraría en 1884 (este último como "Cementerio de Epidemias" a causa de la elevada mortandad por cólera experimentada), pero cuyas obras no finalizarían hasta 1925.

Quien daría lugar a la primera obra de envergadura al respecto sería Faustino RodríguezSan Pedro, del Partido Conservador. Nombrado alcalde el 5 de octubre de 1890, acometería la creación del parque de La Elipa con la plantación de 50.000 árboles. Tres décadas 
después, en los años veinte del siglo XX, La Elipa contaba con un número importante de talleres dedicados a la confección de tejas (actividad hasta hace pocas décadas presente en el barrio), así como a actividades vinculadas con el sector ganadero y textil que atraían estacionalmente población trashumante (la trashumancia en aquel momento era un modo de vida de cientos de miles de personas en toda la Península Ibérica).

A mediados del pasado siglo, concretamente en el año 1951, el ayuntamiento de Vicálvaro fue anexionado a Madrid, dando lugar pocos años después a dos nuevos distritos de la capital española. Hasta la fecha la división del territorio madrileño en distritos era de 1902 y aún no contemplaba como distritos los espacios ganados a los ayuntamientos que se iban anexionando a la ciudad, realidad que se implementaría desde 1955. A partir de la redefinición del espacio urbano, se integraba La Elipa, por un lado, en el barrio de Las Ventas (antiguamente denominado "Las Ventas del Espíritu Santo"), atravesado por la Calle Alcalá, distrito de Ciudad Lineal (el n ${ }^{\circ} 15$ de Madrid); dando lugar por otra parte a Moratalaz, que también pertenecía al viejo ayuntamiento de Vicálvaro, al distrito $\mathrm{n}^{\circ} 14$ de la ciudad. Mientras que Vicálvaro pasaría a ser el distrito $\mathrm{n}^{\circ} 19$ (de los veintiuno en los que se divide Madrid, en los que se agrupan los ciento treinta y un barrios de la ciudad). Y aunque la Quinta de La Fuente del Berro había sido parte central del barrio de Las Ventas, pasaría oficialmente a ser parte integrante del distrito conformado por el Barrio de Salamanca (el distrito $\left.\mathrm{n}^{\circ} 4\right)$.

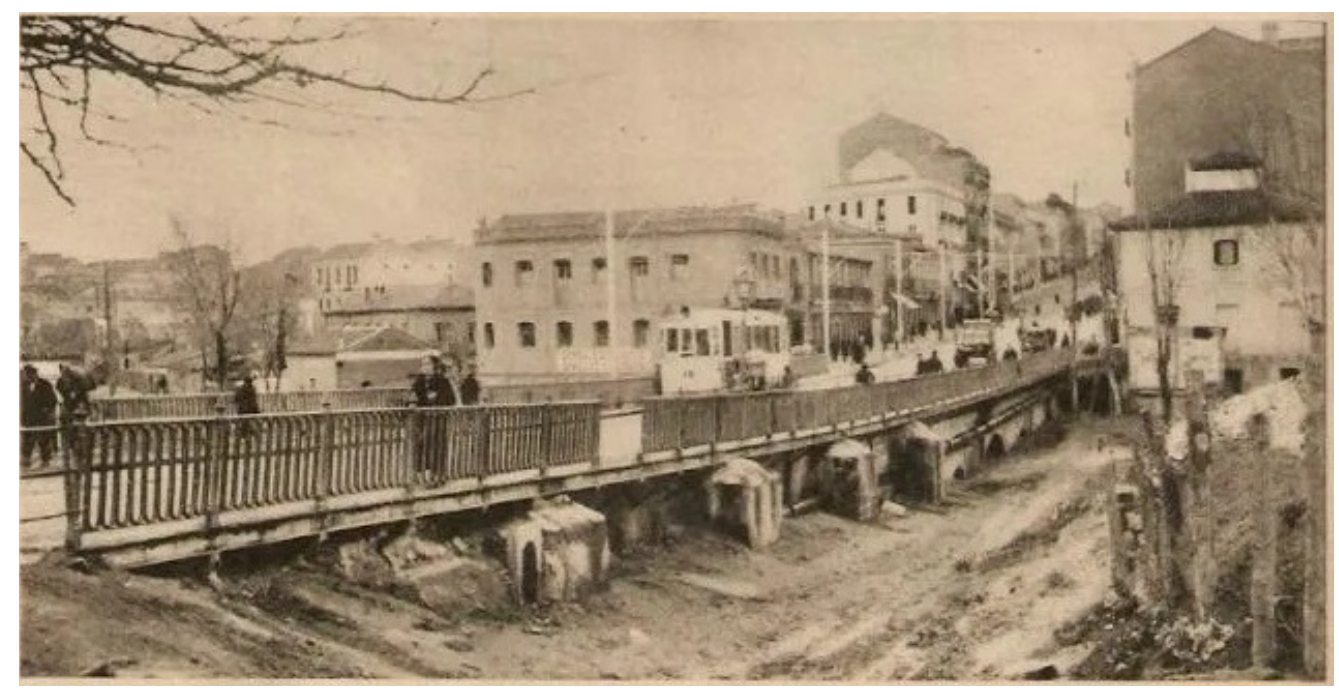

Figura 1. Puente original de Las Ventas en 1930, frente a la recién inaugurada Plaza de Toros. Fuente: Mundo Gráfico, 1930 
Desde aquella década de los años 50 del pasado siglo, miles de emigrantes (de Andalucía, Extremadura, Galicia, Asturias, Castilla...) poblaron aquel espacio, llenando de contenido sus calles y generando riqueza en la ciudad, empleados en diversas fábricas y empresas que irían abriendo a lo largo de los años, dando lugar, asimismo, a la fijación de servicios que, inicialmente, no existían en este nuevo ensanche Este de la ciudad. En los años 70 y 80 los hijos e hijas de aquellos emigrantes se identificaban en su mayoría con su barrio, en el que habían nacido (eran hijos e hijas del barrio), sin perder en su mayoría el vínculo con los lugares de procedencia de sus progenitores (donde veraneaban, escapando del rigor del estío madrileño; tal y como hacen incluso, en innumerables casos, los nietos y bisnietos de aquellos y aquellas emigrantes). Desconociendo los más jóvenes de estos populosos barrios la evolución de este amplio espacio urbano, los usos de sus tierras, los oficios de sus gentes, etcétera, ajenos a estos cambios que resituaron el espacio en cuanto a lindes y función productiva se refiere. Unos cambios que, sin duda, son muy profundos y poliédricos, de tal modo que, como bien indica Florencio Zoido (2019, p. 101):

"la división territorial con valor político-administrativo tiene tal cúmulo de repercusiones sobre el medio natural, la economía y, en definitiva, la territorialidad que afecta a cada sociedad, que condiciona fuertemente sus evoluciones y comportamientos".

Una evolución que ha borrado a su vez la memoria de dichos espacios en favor de una nueva identidad colectiva y narrativas asociadas a lo urbano, frente a los usos agrarios de estos entornos integrados en las ciudades.

\subsection{La Quinta de La Fuente del Berro}

La Fuente del Berro es a día de hoy un parque público de la capital española, situado a $3,8 \mathrm{~km}$ de la Puerta del Sol y a 2,5 km de El Retiro, en el Este de la ciudad, con Latitud: 40.42513105 y Longitud: -3.66423759698396 . Convertido en zona de recreo propiedad del ayuntamiento, es una vieja quinta que se desarrollaba a lo largo del arroyo del Abroñigal, afluente del río Manzanares, presentando un entorno ajardinado con cerca de $53.000 \mathrm{~m} 2$ (si bien en origen sumaba más de $80.000 \mathrm{~m} 2$ ).

Muy conocida por sus cristalinas y abundantes aguas, de manera remota parece que su origen se situaría a mediados del siglo XVI. El primer propietario del que hemos tenido constancia sería Juan de la Vega, quien compraría hacia 1542 aquella inmensa finca. Cultivaría melones en aquel rico espacio, que pasaría a conocerse como "Huerta de Zamora" (Monte-Cristo, 1924). Seis décadas después, el aristócrata 
Juan Fernández de Velasco, quinto duque de Frías (así como IV marqués de Berlanga, VII conde de Haro, VI condestable de Castilla y gobernador del ducado de Milán), pasaría a ser el propietario de aquellos jardines entre 1609 y 1630, en los que pretendía fijar su residencia de descanso. Denominaría a aquel paraje "Quinta de Miraflores" (aunque sería conocida popularmente como "Huerta de la Fuente del Berro" o "Quinta de Frías" (Baztán, 1959, p. 141). El proyecto quedaría inconcluso por la muerte de Fernández de Velasco en 1613. En el año 1630 Felipe IV compraría aquella propiedad, por una suma de 32.000 ducados, coincidiendo con el inicio de las obras de El Retiro. Desde 1639 en adelante ocuparían aquella magnífica quinta monjes castellanos expulsados del Monasterio de Montserrat (Lezcano, 1973, p. 28 y ss.). Si bien la Casa Real se aseguraría para su disfrute las reputadas aguas de la Fuente del Berro, siendo muy apreciadas las aguas de aquel paraje por los monarcas españoles a lo largo de los siglos (primero los Austrias, después los Borbones). Basta recordar como la reina María Luisa de Orleans, reina consorte de Carlos II (el hijo más joven de Felipe IV), solo bebía agua de aquel espacio natural, según indicaba Francisco Baztán al respecto (1959, p. 254):

“(...) en 1686 se dispuso por la Reina que toda el agua que se sirviese para su real persona procediese de la Fuente del Berro, estableciéndose un servicio especial para el transporte de agua, una o dos veces, por semana...”.

Siguiendo esta tradición, en el siglo XVIII sería de hecho conocido este paraje como "La Fuente del Rey", dado que el monarca Carlos III lo cerraría excluyendo otros usos que no fuesen el abastecimiento de la Casa Real, si bien la Quinta de La Fuente del Berro era propiedad desde 1703 de María Trimiño Vázquez de Coronado (MonteCristo, 1924), Adelantada de Costa Rica (quien a su muerte cedería aquel paraje a la Obra Pía de los Padres Mercedarios Calzados). A finales de siglo, concretamente en 1798, Martín Estenoz adquiría la finca de la Quinta de la Fuente del Berro, en subasta pública, mandando construir a su alrededor un muro que hoy se conserva en parte.

A mediados de aquel siglo se mencionaría en las Respuestas Generales del Catastro del Marqués de Ensenada (1750-1754) el "Arroyo del Abroñigal”, transcrito como "Arroio de Breñigal". En el marco de los lindes del término municipal de Vicálvaro se haría constar que este confrontaba a "Levante con el Rio Del Jarama y término de Rivas a Poniente con el Arroio de Breñigal y al Norte con el Lugar de Canillas Ambrox y Coslada" (1751, p.201). 


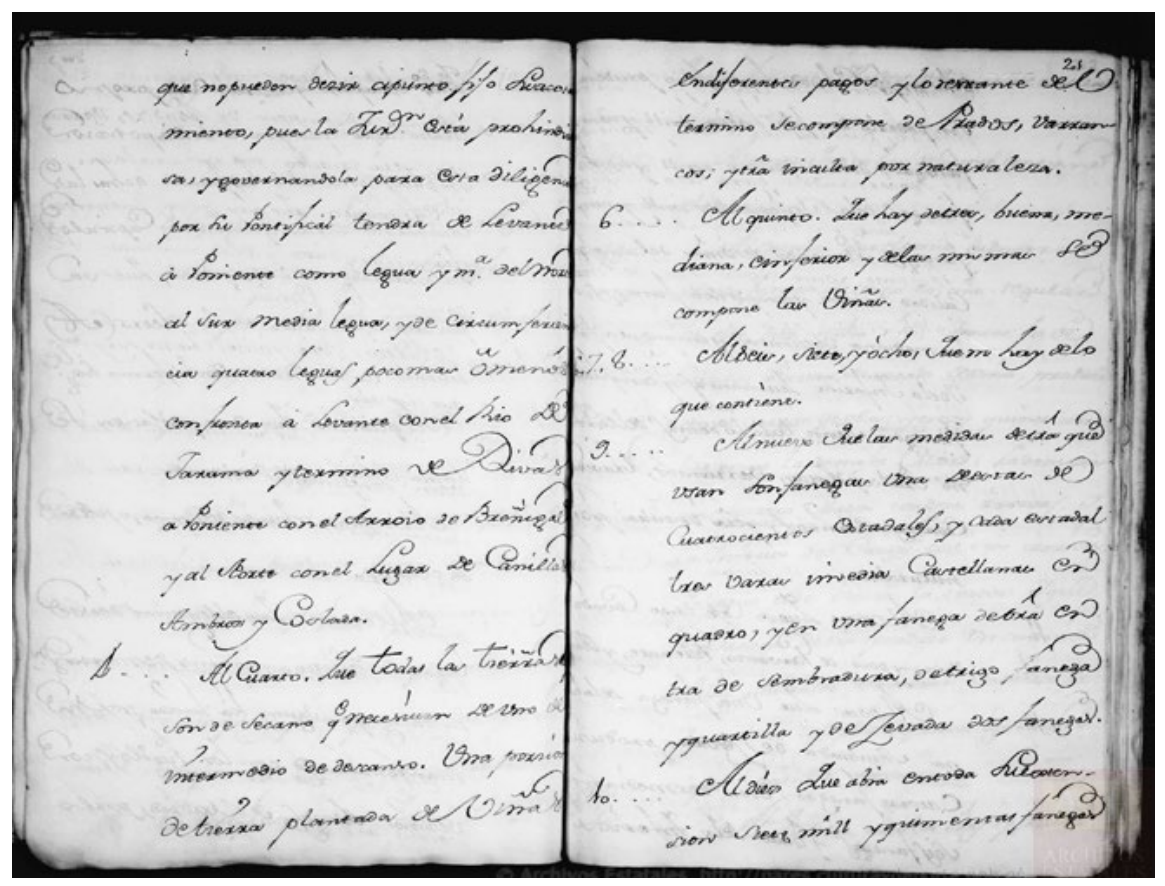

Figura 2. El Arroyo del Abroñigal en Respuestas Generales del Catastro del Marqués de Ensenada (1750-1754). Fuente: Portal de Archivos Españoles (PARES)

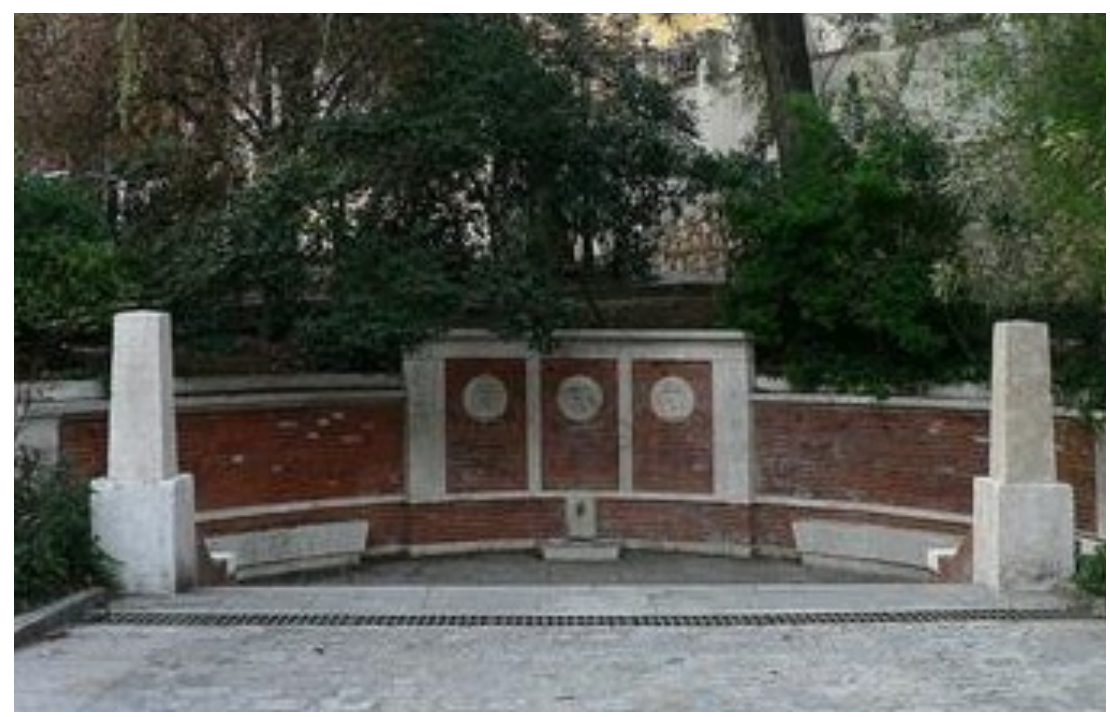

Figura 3. La Fuente del Berro, al pie de la Calle Peñascales, que da nombre a la quinta y parque. Su actual diseño data de inicios de la década de los años 50 del pasado siglo XX. 
En aquellos tiempos el oficio del aguador estaba muy presente en el día a día (Del Río, 1993, pp. 35-46), encargados de llevar a las casas de los pudientes aristócratas y burgueses aguas de manantiales y fuentes limpias. A finales del aquel siglo XVIII, justamente, entre los aguadores más conocidos debemos mentar a Pedro Chamorro (Pedro Collado), quien conoció al monarca Fernando VII cuando aún se ganaba la vida de aguador de La Fuente del Berro, pasando a ser íntimo del monarca, sobre el que llegaría a tener una gran ascendencia (Baroja, 1933, pp.156-157).

Pascual Madoz en su Diccionario geografico estadístico-histórico de España y sus posesiones de ultra-mar (Tomo X, 1847), cita entre de las más sonadas fuentes públicas de Madrid La Fuente del Berro, indicando que hasta la fecha las aguas potables de la ciudad procedían de cuatro grandes caudales, concretamente de la Fuente Castellana, de Alcubilla, del Abroñigal alto y del Abroñigal bajo (Madoz, 1847, p.700). En aquel momento el propietario de la Quinta de La Fuente del Berro era Casimiro Domínguez Gil, quien en 1861 solicita al ayuntamiento de Madrid permiso para construir una vivienda de planta baja, en la práctica el pequeño palacete que aún se conserva aprovechando el ensanche que se estaba proyectando en la ciudad en la zona norte, este y sur de la ciudad.

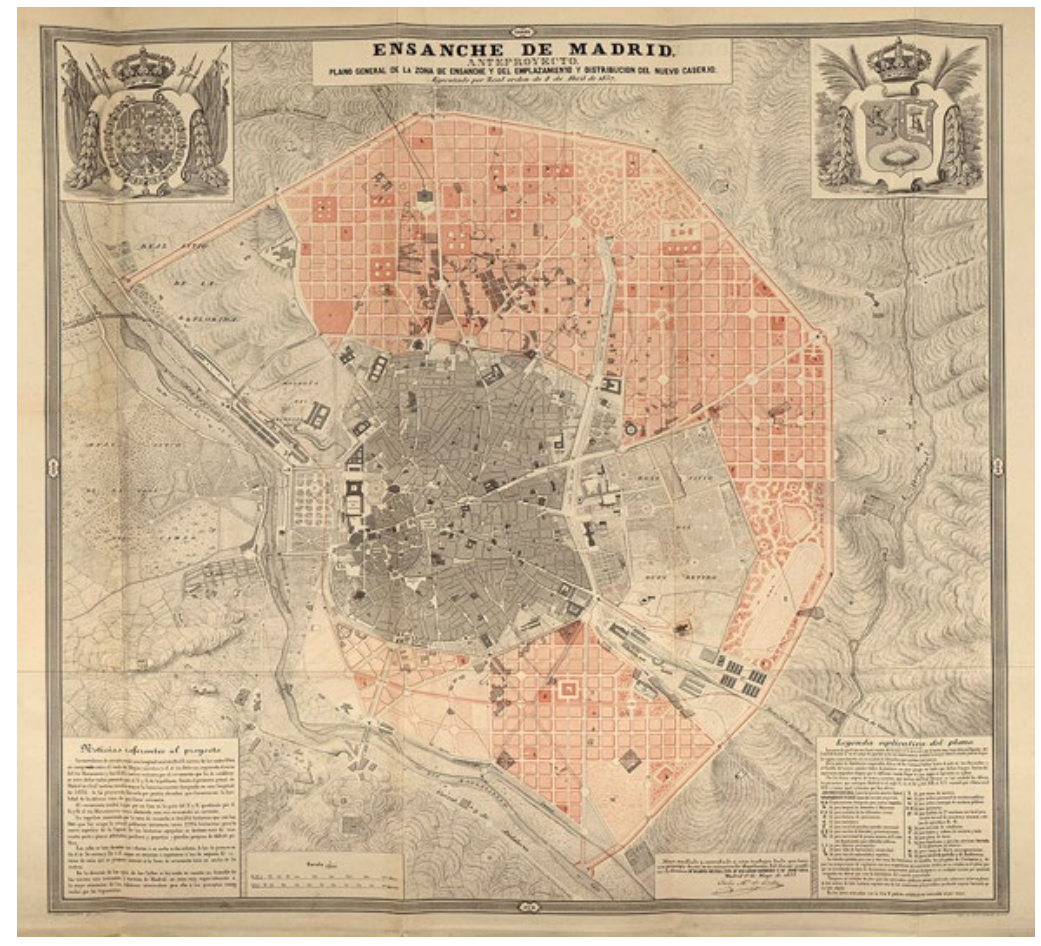

Figura 4. Plano General del Anteproyecto de Ensanche de Madrid de 1861, de la autoría de Carlos Ma de Castro. Fuente: Biblioteca Digital Hispánica 


\subsection{Un espacio natural insertado en la ciudad}

En 1900 se daría lugar a varias construcciones en dicho espacio a modo de parque de atracciones, dándole el nombre de "Nuevos Campos Elíseos" (Monte-Cristo, 1924). Este proyecto no tuvo fortuna y a inicios del siglo XX caería en absoluto desuso. En las primeras décadas del siglo XX se urbanizaría el entorno de aquel paraje en su parte norte y, sobre todo, oeste. Entre 1926 y 1929 -en dos fases- se construyeron chalets de una y dos plantas, de los que se conserva parte. En total se levantaron 184 casas (conocidas en la época como 'hotelitos') bajo el diseño del arquitecto Enrique Pfitz y López. Un conjunto urbano que corrió peligro en los años 60 y 70, pero que desde 1984 pasó a ser zona protegida.

Entre medias, a lo largo de la década de los 20 y 30 habían comprado la Quinta de La Fuente del Berro un matrimonio holandés, de apellido Van Eeghen, dando lugar aquel paraje a encuentros de la aristocracia madrileña de la época, tal y como se podía leer en las páginas de Blanco y Negro (Monte-Cristo, 1924). Después de ser propiedad de otras figuras notables de la ciudad, en junio de 1948 el Conde de Mayalde, alcalde de Madrid, consumaría la adquisición municipal de la Quinta de La Fuente de Berro, comprándola a su propietario por aquellas fechas, Mauritz van Eehgen (sobrino de Martín de Estenoz, que en 1798 la había adquirido) por importe de 6.700 .000 pesetas. Poco antes, La Fuente del Berro había sido declarada "Jardín Artístico" en un decreto de finales de julio de 1941 (modificado en enero de 1946).

En 1953 se crearía el Instituto Arqueológico Madrileño, con sede en el viejo palacete de la Quinta de La Fuente del Berro, bajo la dirección de Julio Martínez Santa-Olalla y el apoyo del alcalde de Madrid José María de la Blanca Finat y Escrivá de Romaní, conde de Mayalde (Carrera Hontana et al., 2017, p. 1783). Casona que décadas después pasaría a ser centro cultural, rehabilitándose totalmente en 2003.

El magno espacio de la Quinta de La Fuente del Berro se vería reducido por el inicio de las obras de la M-30 en 1970 (aprovechando en gran medida el cauce del Arroyo del Abroñigal -que sería subterráneamente canalizado-), pasando a ocupar la zona ajardinada 7,4 hectáreas. Desde aquel momento hasta la fecha, aquel paraje ha visto crecer a múltiples generaciones de niños y niñas del barrio de La Fuente del Berro y del barrio de Las Ventas.

Un espacio ajardinado de enorme riqueza natural (Souto Alcaraz, 1994) que va a contar con un atractivo adicional, tal y como se anunciaba en la prensa en enero de 2020. Concretamente pasarán a ser visitables las galerías subterráneas, tipo mayrat (término árabe que refiere la canalización de cursos de agua subterráneos), con las que cuenta La Fuente del Berro y que antaño se empleaban para el regadío de fincas de aquel entorno madrileño (Llamas, 1976). 


\section{POTENCIAL DIDÁCTICO DE LA QUINTA DE LA FUENTE DEL BERRO}

Como se ha indicado, la intrahistoria y la realidad natural de la Fuente del Berro es especialmente rica. Este paraje se presenta como un espacio en el que trabajar de manera privilegiada la relación entre el espacio y el paso del tiempo, y las interacciones del ser humano sobre el medio físico en distintas etapas y con diversas funciones (Calaf et al., 1997). La vieja quinta puede emplearse a nivel escolar en su conjunto contribuyendo a explicar, principalmente, la evolución del espacio urbano madrileño. Indicando como este espacio fue rural antes que urbano, formando parte del gran ensanche urbano de la parte Este de Madrid, explicando a qué respondió dicho proceso. Asimismo, el propio espacio físico puede y debe ser trabajado (a nivel natural, geológico...). A continuación propongo integrar, como recurso educativo, el Parque de la Quinta de la Fuente del Berro en la dinámica docente de la Educación Secundaria Obligatoria (ESO).

Después de una introducción en el aula de dicho paraje, se podría diseñar una salida didáctica desde el centro escolar y llegada a La Fuente del Berro. Entendiendo que debemos incorporar a nuestra docencia el medio como recurso, integrándolo en nuestro día a día (Vilarrasa, 2003, p. 5), llevando la escuela "a todos aquellos espacios en los que se hace posible la vivencia de experiencias culturales sobre las que construir el conocimiento y acercar el aprendizaje disciplinar a la experiencia".

El docente o la docente podría diseñar un itinerario didáctico en el que se marquen diversas paradas en las que explicar el espacio, así como interrogar al alumnado por el mismo (¿Qué ve el alumnado cuando camina por la ciudad? ¿Sobre qué reflexiona al caminar por nuestras calles? ¿Se interroga sobre los nombres y diseños de las calles? ¿Se interroga sobre la evolución del medio?, etcétera). Fomentar la interacción y la reflexión sobre el espacio será clave, a mi entender, para conseguir un completo proceso de enseñanza-aprendizaje sobre el entorno urbano y su evolución, fomentando la participación del alumnado en su formación en el marco del conocimiento del medio, contribuyendo a la conformación de un espíritu crítico y una conciencia ciudadana.

La mejor opción sería escapar de la tradicional "visita", que no trabaja el contexto y se centra en objetos musealizados sin posibilidad alguna de interactuar con los mismos. Naturalmente, ese itinerario debe partir de unos objetivos bien definidos, evitando saturar de información al alumnado. Se podría centrar este itinerario en la riqueza natural del entorno de La Fuente del Berro y aquellos espacios previos que entre este paraje y el centro escolar nos iríamos encontrando -previamente seleccionados-, así como sobre la historia y el patrimonio cultural material vinculado con dicho vergel. Sería de gran interés que antes de realizarse el itinerario didáctico se trabajase en el aula con fotografías de época, realizándose un comentario sobre las mismas, que podrían, asimismo, compararse con imágenes de la actualidad. Por ejemplo, se podrían comparar 
varias imágenes históricas del puente de Las Ventas, comparándolo con el actual puente y los usos del espacio visibles en dichas imágenes.

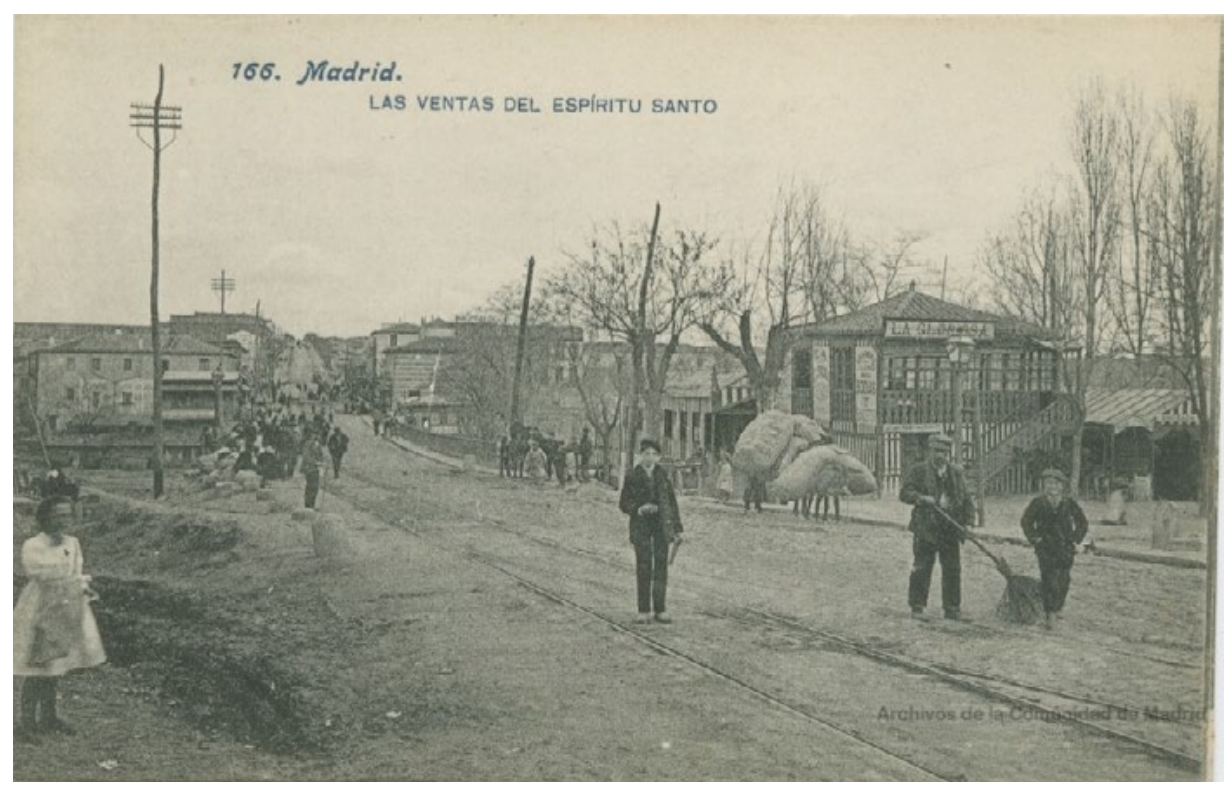

FIgura 5. Postal de Las Ventas del Espíritu Santo a inicios del siglo XX. Fuente: Archivos de la Comunidad de Madrid (Ref. ES 28079 ARCM 0372R)

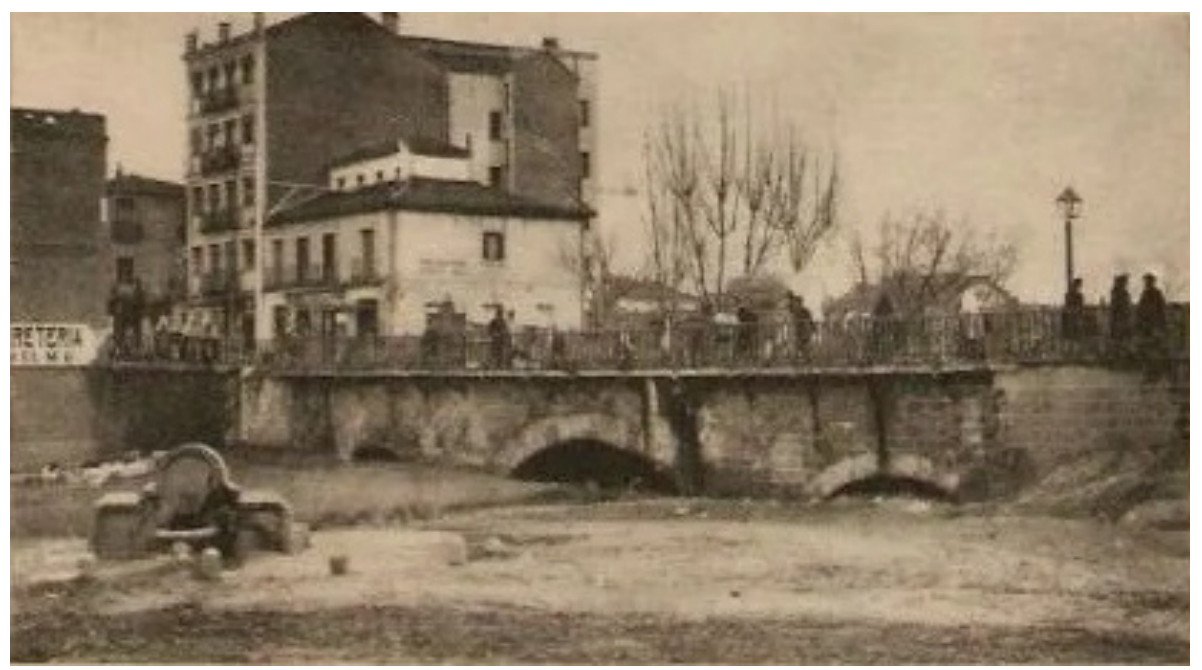

Figura 6. Puente de Las Ventas, Mundo Gráfico, 1930 


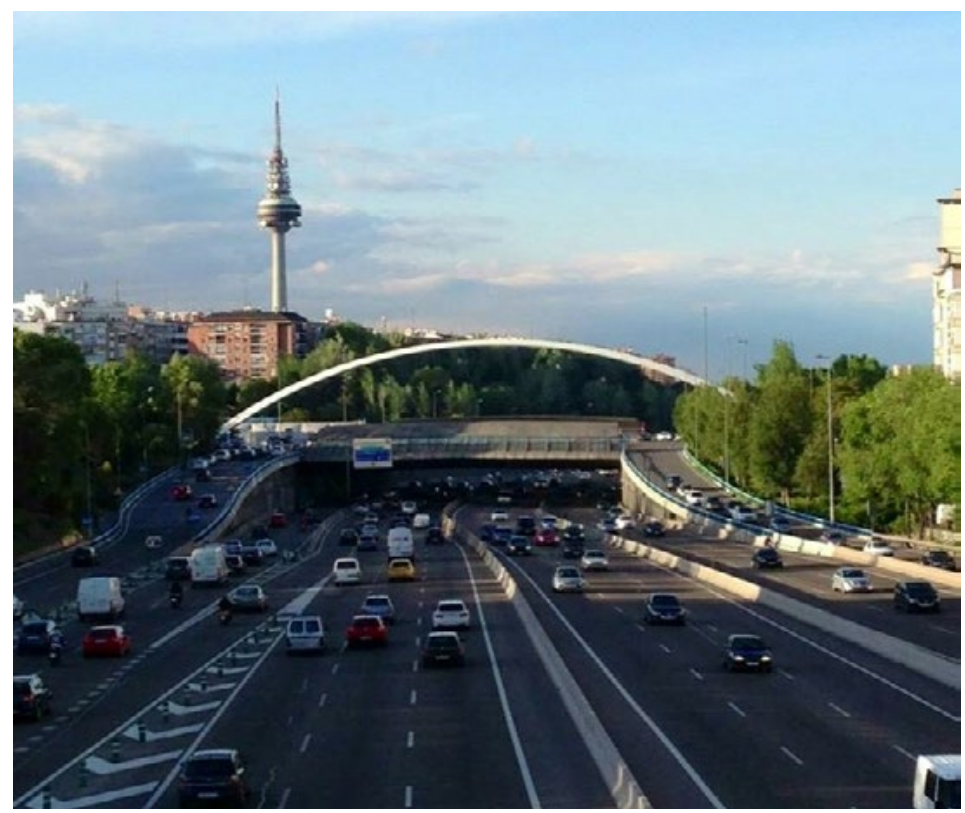

Figura 7. Puente de Las Ventas, con Torrespaña al fondo, 2013

Al margen del alumnado de la ESO, igualmente se podrían diseñar itinerarios dirigidos a alumnado de Educación Primaria. En este caso el diseño de las calles o los tipos de construcción podrían ser elegidos para realizar dos o tres paradas y reflexionar sobre el espacio urbano. Se podría reflexionar sobre los usos del espacio a lo largo del tiempo (reflexionando sobre lo rural que ha dejado paso a lo urbano), así como sobre los materiales constructivos y las alturas de los edificios que se han ido construyendo (observando como los predios más antiguos cuentan con menos alturas, y como han ido variando las estéticas de las fachadas, aunque siga muy presente el ladrillo visto en las mismas).

Si nos centramos en el alumnado de $3^{\circ}$ o $4^{\circ}$ de la ESO podríamos reflexionar sobre el porqué del cierre de numerosos negocios de barrio que había en los bajos de muchos de los edificios que nos iríamos encontrando a lo largo del itinerario en favor de los grandes centros comerciales que están a las afueras de la ciudad (con lo que esto implica, en diversos aspectos, desde el ámbito económico hasta el medioambiental...). Reparar en el nombre de las calles y la presencia (parcial) de la toponimia histórica es muy interesante para trabajar el espacio (la propia denominación de "La Fuente del Berro", de la "Plaza de las Ventas", de "Las Ventas del Espíritu Santo" o de "La Elipa", puede ser muy sugestiva).

En este orden de cosas, y llegando a la Quinta de La Fuente del Berro, se presenta de especial interés introducir los oficios tradicionales, que ayudarán al alumnado (singularmente al de los centros escolares del barrio de Las Ventas y de Fuente del Berro) 
a comprender esa evolución del espacio (de su espacio) a lo largo del tiempo. Oficios que nos remiten, singularmente, en el entorno espacial que hemos escogido para este artículo a aguadores y tejeros (concretamente en el entorno de La Elipa existieron, hasta bien entrado el siglo XX, varios tejares). El oficio del aguador, por ejemplo, contribuirá a visibilizar la importancia del agua en perspectiva histórica, en cuanto recurso natural finito y muy preciado. Aunque actualmente en prácticamente todos los hogares exista traída de agua, sigue siendo éste un bien tan escaso como esencial (que, con independencia de su status social y económico, monarcas y aristócratas hacían buscar de la Fuente del Berro hasta hace apenas poco más de un siglo atrás), realidad que en tiempos de cambio climático cobra, si cabe, mayor actualidad. A tal efecto, se podría trabajar con las descripciones que las Respuestas Generales del Catastro del Marqués de Ensenada presentan de este entorno (y otros) de Madrid. Si nuestro alumnado fuese universitario, podríamos encomendarle que diseñara, por grupos, su propio itinerario didáctico con aquellas paradas (y objetivos aparejados) que entendiesen oportunas. Hay al respecto diversas experiencias de gran interés que se han ido diseñando en los últimos treinta años en relación a otras ciudades y parajes, de la autoría de varias generaciones de especialistas en la Didáctica de las Ciencias Sociales (García et al., 1993; García Pérez et al., 2007; Medina et al., 2016).

Atendiendo a su cercanía con el Parque de la Quinta de La Fuente del Berro, podrían emplear el presente artículo los centros de enseñanza del barrio de Las Ventas y de La Fuente del Berro (los centros públicos CEIP San Juan Bosco, CEIP Gustavo Adolfo Bécquer y el IES Francisco de Goya, así como los concertados Colegio Nuestra Señora de las Victorias, el Colegio Nuestra Señora de la Merced, el Colegio Espíritu Santo, el Colegio Santa Susana o el Colegio Santa Ana y San Rafael -así como, naturalmente, cualquier otro que lo estime de interés-).

Si nos centramos, como advertía en un inicio, en el aprovechamiento didáctico del espacio que nos ocupa al servicio de la enseñanza-aprendizaje del medio (físico, social y cultural) y del tiempo, atendiendo al Decreto 48/2015, sugiero trabajar el Parque de la Quinta de La Fuente del Berro en las materias de la ESO "Geografía e Historia" y "Biología y Geología". En Geografía e Historia de $1^{\circ}$ de la ESO concretamente para el Bloque 1 "El medio físico", particularmente para el tema "3. Los elementos del medio físico. España, Europa y el mundo: relieve, hidrografía; clima: elementos y diversidad; paisajes; zonas bioclimáticas; medio natural: áreas y problemas medioambientales". En el $2^{\circ}$ curso de la ESO también sería de utilidad trabajar el proceso histórico de la Fuente del Berro y del ensanche urbano del que es ejemplo para el Bloque 2 "El espacio humano. España, Europa y el mundo: la población; la organización territorial; modelos demográficos, movimientos migratorios; la ciudad y el proceso de urbanización"; así como también en el Bloque 2 se podría trabajar dicho paraje y ensanche urbano en el marco del tema "La actividad económica y los recursos naturales" los oficios tradicionales 
y la evolución que ha experimentado el espacio a respecto de sus habitantes y los usos del mismo. Cuestión que se podría reforzar en $4^{\circ}$ de la ESO, igualmente en Geografía e Historia, en el marco del Bloque 3 "La revolución Industrial", con especial atención al tema "2. La revolución industrial en España. La discusión en torno a las características de la industrialización en España: ¿éxito o fracaso?”.

En la materia Biología y Geología de $1^{\circ}$ de la ESO, el Bloque 1 "Habilidades, destrezas y estrategias. Metodología científica" y el Bloque 2 "La Tierra en el universo", se podrían trabajar sobre este espacio natural obteniendo y seleccionando información in situ a partir de la recogida de muestras del medio natural, como reza el Decreto 48/2015, analizando en el aula dichas muestras de restos geológicos (tras la selección, la recogida pueda ser fotográfica a favor de la preservación del espacio). En el Bloque 2 "La Tierra en el universo", asimismo, se desarrollarían en el centro escolar, con el apoyo de La Fuente del Berro, los temas 5 y 7 del Decreto 48/2015, "Los minerales y las rocas: sus propiedades, características y utilidades" y "La hidrosfera", respectivamente. En este nivel educativo, por último, sugiero trabajar el Bloque 6 "Los ecosistemas", realizando fotografías en una salida didáctica a La Fuente del Berro en la que se realizarían diversas fotografías sobre las que identificar en el aula factores abióticos y bióticos, así como saber diferenciar ecosistemas acuáticos y ecosistemas terrestres. Las imágenes se compararían con otros emplazamientos que presenten características diferentes a las de dicho paraje.

En el curso $3^{\circ}$ de la ESO el Bloque 5 "El relieve terrestre y su evolución" tendría un magnífico encaje en el marco del Parque de la Quinta de La Fuente del Berro, particularmente los temas "1. Factores que condicionan el relieve terrestre" y "2. Las aguas superficiales y el modelado del relieve". En $4^{\circ}$ de la ESO el Bloque 2 "La dinámica de la Tierra" y el Bloque 3 "Ecología y medio ambiente" igualmente se podría trabajar con apoyo de este magnífico recurso educativo que es La Fuente del Berro.

Si pensamos, asimismo, en el alumnado de $1^{\circ}$ y $2^{\circ}$ de Bachillerato, el Parque de la Quinta de la Fuente del Berro podría emplearse como recurso educativo en las materias troncales "Historia del Mundo Contemporáneo" ( $1^{\circ}$ curso), "Historia de España" ( $2^{\circ}$ curso) y "Geografía". Dado que dicho emplazamiento y su entorno puede ser trabajado en perspectiva histórica, sobre todo a partir de la relación de propietarios que ha tenido este paraje y el hilo conductor que lo vincula con los Austrias y los Borbones (recreando hábitos, costumbres, la estratificación social, etcétera, en el tránsito entre el Antiguo Régimen y la Edad Contemporánea -incluido el proceso de industrialización y el final de los usos agrarios del entorno-), así como desde el plano físico y los diversos aprovechamientos del espacio y su transformación en favor de la modernización del mismo.

A lo ya señalado, debemos indicar que en el Parque de la Quinta de La Fuente del Berro se han ido sumando elementos desde su municipalización a mediados de los 50 del pasado siglo, que se han incorporado al parque como elementos definitorios. Un 
patrimonio material con el que aumenta su potencial didáctico dicho paraje y con el que también se podría trabajar en materias de bachillerato como las troncales "Lengua Castellana y Literatura", "Literatura Universal", "Fundamentos del Arte", "Dibujo Técnico" o las específicas opcionales "Dibujo Artístico" e "Historia de la Música". Y es que nos encontramos estatuas de insignes músicos, escritores, pintores y otros creadores que pueden ser introducidos en el aula gracias a dicho espacio. Monumentos como los dedicados al violinista Enrique Iniesta, al poeta Gustavo Adolfo Bécquer o al escritor ruso Alexander Pushkin.

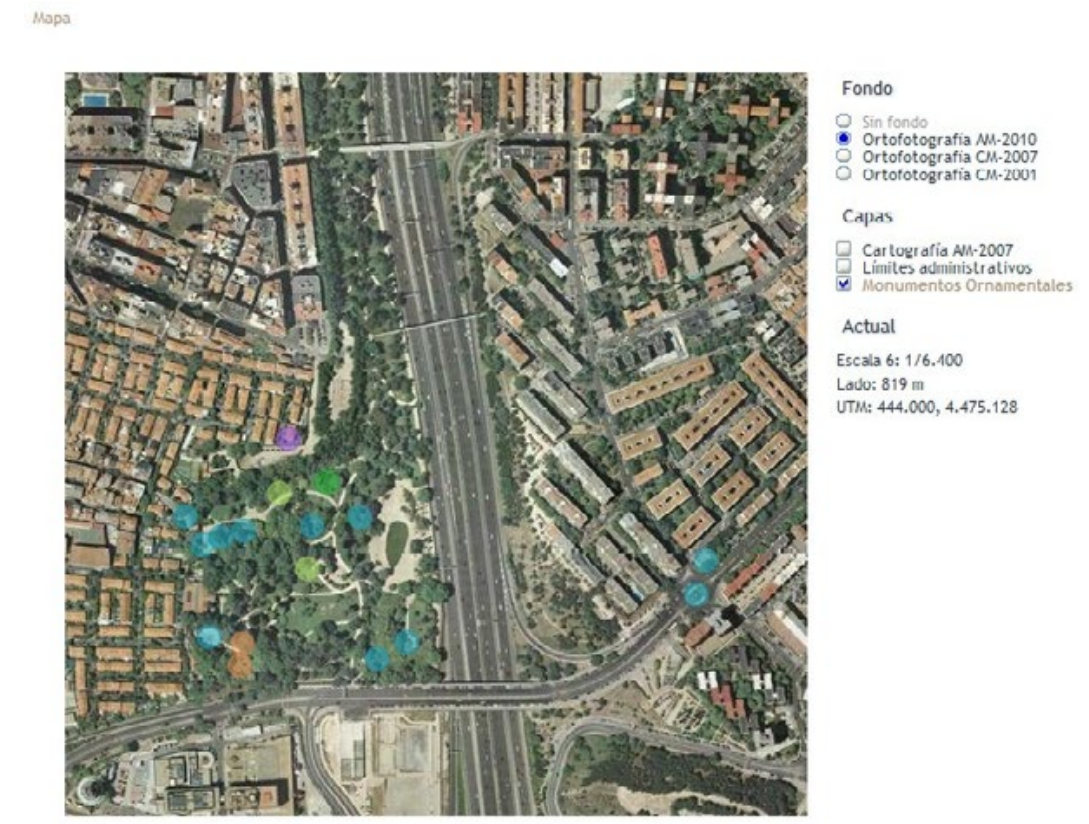

FIGURA 8. Ortofotografía en la que se pueden visualizar distintos monumentos del Parque de La Fuente del Berro. En la parte inferior izquierda se puede ver Torrespaña y todo el complejo de TVE, así como la divisoria que supone la M-30 entre La Elipa y Fuente del Berro.

Fuente: http://www.monumentamadrid.es

Este patrimonio material ubicado en el Parque de la Quinta de La Fuente del Berro podría dar lugar a un itinerario centrado en la Literatura y Música Contemporáneas (en el que integrar las dos esculturas abstractas de la autoría de Fernando González Calisavo, y las fuentes y estanques -nueve en total- de este vergel), a partir de tres esculturas erigidas en homenaje a figuras destacadas de la cultura europea (marcadas en verde en la ortofotografía que se presenta en la Fig. 8) y que referenciamos a continuación: 
-Gustavo Adolfo Bécquer (Sevilla, 1836-Madrid, 1870). Poeta y escritor que pasaría a la historia como uno de los máximos exponentes del Romanticismo. Entre sus obras destacar Cartas desde mi celda (Madrid, 1864), Libro de los gorriones (manuscrito de 1868) y sus Rimas (compendio de poemas salvados por sus amigos, 1871).

-Alexander Pushkin (Moscú, 1799-San Petersburgo, 1837) fundador de la novela rusa moderna. Creador de un estilo de narrativa que mezclaba el drama con lo romántico y la sátira, influenciando a la mayor parte de los escritores rusos integrantes de la siguiente generación a la suya.

-Enrique Iniesta Cano (Madrid, 1906-Mendoza 1969). Virtuoso violinista, que fundó la Agrupación Nacional de Cámara. Después de hacer carrera en España, ejercería en Chile y, finalmente, en Mendoza (Argentina), donde sería profesor de la Escuela Superior de Música y concertista de la Orquesta Sinfónica.

Podríamos sumar a nuestro itinerario, por último, la placa que está situada en la parte norte de la Quinta de La Fuente del Berro al pie de la Calle Gabriel Abreu n ${ }^{\circ} 11$. Dedicada a José Padilla Sánchez (Almería, 1889-Madrid, 1960). Compositor y músico, autor de melodías muy conocidas, caso de La Violetera (cuplé compuesto en 1914, con letra de Eduardo Montesinos) o El Relicario (pasodoble compuesto en 1914, con letra de Armando Oliveros y José María Castellví). A través de las letras de estas y otras piezas se podría analizar en el aula el contexto histórico y la función de la literatura y la música a lo largo del tiempo.

En definitiva, es evidente que el Parque de la Quinta de la Fuente del Berro presenta unas amplias y múltiples posibilidades didácticas para trabajar el conocimiento del medio (geográfico, histórico, social y cultural). Para ello es necesario abandonar una idea estática de la ciudad y reconstruir desde el presente el rico pasado de todo espacio urbano, recreándolo en su rica diversidad.

\section{BIBLIOGRAFÍA}

Baroja y Nessi, P. (1933). Juan Van Halen el oficial aventurero. Madrid, Espasa-Calpe. Baztán, F. (1959). Monumentos de Madrid, Sección de Cultura. Artes Gráficas Municipales.

Calaf Masachs, R., Suárez Casares, Mª́. \& Menéndez Fernández, R. (1997), Aprender a enseñar Geografía, Barcelona: Oikos-Tau.

Camarero Bullón, C. (2002). El Catastro de Ensenada, 1749-1756 (catálogo de la exposición). Magna averiguación fiscal para alivio de los vasallos y mejor conocimiento de los reinos, Madrid: Centro de Publicaciones y Documentación del Ministerio de Economía y Hacienda. 
Carrera Hontana, E. et al. (2017). El Museo de San Isidro. Un siglo de arqueología en Madrid. Boletín del Museo Arqueológico Nacional, 35, 1780-1787.

Del Río López, Á. (1993). Viejos oficios de Madrid. Madrid: Ediciones La Librería.

García, F. F., Álvarez, C., Carmona, M., Civantos, J., Guerrero, G., Román, T. \& Villanueva, A. (1993). Vivir en la ciudad: una unidad didáctica para el estudio del medio urbano. Investigación en la escuela, 20, 39-64.

García Pérez, F. F. (2007). Urbes locales y valores cívicos universales. La enseñanza en los espacios urbanos. In Ma J. Marrón Gaite, J. Salom y X.M. Souto (Eds.), Las competencias geográficas para la educación ciudadana (pp. 201-220). Valencia: Universitat de València y Grupo de Didáctica de la Asociación de Geógrafos Españoles.

Lezcano, A. (1973). Madrid, sus cosas y sus gentes. Madrid: Prensa Española.

Llamas Madurga, R. (1976). La utilización de aguas subterráneas en Madrid. De los 'mayrat' musulmanes a los modelos digitales. Estudios geológicos, 32 (1). 121139.

Madoz, P. (1847). Diccionario geográfico estadístico-histórico de España y sus posesiones de ultra-mar (Tomo X). Madrid: Establecimiento tipográfico de $\mathrm{P}$. Madoz y L. Sagasti.

Medina, S.; Arrebola Haro, J. C.; Mora Márquez, M.; López Fernández, J. A. (2016). Propuesta de itinerario interdisciplinar en la formación del profesorado e Educación Primaria en el ámbito de las Ciencias Sociales y Experimentales. Didáctica de las Ciencias Experimentales y Sociales, 31, 79-97. https://doi. org/10.7203/dces.31.8058

Monte-Cristo (27/07/1924). Residencias Campestres. La Quinta del Berro. In Blanco y Negro, pp. 39-41.

Souto Alcaraz, Á. (1994). Fuente del Berro. Madrid: Fundación Caja de Madrid / El Avapiés.

Souto González, X. M. (1999). Didáctica de la Geografía. Barcelona, Ediciones del Serbal.

Vilarrasa, A. (2003). Salir del aula, Íber. Didáctica de las ciencias sociales, geografía e historia, 36, 5-6.

Zoido Naranjo, F. (2019). Notas a propósito del 'modelo territorial español' y propuesta sobre competencia estatal en ordenación del territorio y paisaje ante una nueva revisión de la Constitución de 1978. In Farinós Dasí, J.; Ojeda Rivera, J. F. \& Trillo Santamaría, J. M. (Coods.) España: Geografías para un Estado posmoderno (pp. 101-104). Madrid/Barcelona, AGE-Geocrítica. 